\title{
DETERMINING SMART INTERSECTIONS FOR SMART CITY APPLICATIONS USING MULTI-CRITERIA DECISION-MAKING TECHNIQUES
}

\author{
T. Urfal1 ${ }^{1}$, A. Eymen ${ }^{2, *}$ \\ ${ }^{1}$ Tokat Technical Sciences Vocational School, Department of Architecture and Urban Planning - tugrul.urfali@gop.edu.tr \\ ${ }^{2}$ Engineering Faculty, Geomatic Engineering, Erciyes University, Kayseri, Turkey - ageymen@erciyes.edu.tr
}

Commission VI, WG VI/4

KEY WORDS: Smart City, Smart City Applications, Geographical Information Systems, Analytical Hierarchy Process, MultiCriteria Decision Techniques, Smart Intersection

\begin{abstract}
:
Urbanization process occurs unprecedentedly all round the world. Increase in population accompanies energy need, environmental issues and transportation problems. In order to manage urban growth which causes complication and to enhance the quality of life, we need to find new solutions. During the recent years, smart cities which solve their problems become popular thanks to integration between reformed technology and expanding cities. Primarily, it requires that smart city should be effective spatially. Due to these reasons, to have an investment to the area of requirement properly is extremely important with regard to cost and recovery in order to benefit from smart city applications ultimately and also to achieve high efficiency from this high budget investment. In this study, the criteria affecting the location of the intersections where the smart intersection system will be applied according to the current situation in Kayseri province by using the multi-criteria decision making method were examined. With these effective solutions, smart transportation will provide high functionality and a more efficient flow. At the same time, this study will help decision-makers in planning and investments.
\end{abstract}

\section{INTRODUCTION}

Today, the rapid development of technology has turned the cities into living centres with crowded population, with the increasing migration from rural to urban (Cengiz et al., 2017). In the face of increasing population, urbanization rate and consumption factors, urban environment, natural environment and energy problems are growing. Urban life and urban design should be innovated by using technology opportunities that develop against the increasing need for energy, environmental problems and urban growth (Sinmaz, 2013).

Many problems such as demographic changes, irregular urbanization, migration and the transportation, energy, health and waste management experienced around the world are challenging the infrastructure of the cities. New planning and design approaches, defined as sustainable smart cities, offer solutions to common problems of developing and growing cities. Smart city solutions should be supported with accurate analyses and implemented with planned preliminary studies. Smart city applications are thought to be successful if they are made in planned and suitable locations to obtain efficiency. (Gruen, 2013).

The "smart city" concept, which was put forward with the aim of making cities more liveable with the opportunities provided by technology, has rapidly gained popularity in recent years. As in all the world, the smart city concept is gaining importance in Turkey (Daniel and Doran, 2013). The concept of smart cities is based on the main idea of creating sustainable cities by combining information technologies with city management processes. Within this concept, it is aimed to create a new lifestyle by using information technologies, geographic information systems, digital and mobile technologies for actions and works in every aspect of human life, from environment to health, security to waste management and efficient management of energy resources. The smart city is usually represented by 6 components: smart economy, smart life, smart environment, smart people, smart transportation and smart management. If all these components are in balance, a city can fulfil its demand for sustainability and quality of life. In other words, a city can be called "smart" if its investments in human and social capital and traditional and modern information and communication technologies, information and communication infrastructures are intelligently support sustainable economic development and a high quality of life (Gruen, 2013).

Intelligent transportation systems are Information Communication Technologies (ICT) supported integrated systems used to solve transportation problems. With the developing cities, the rapid increase in the number of vehicles with each passing day, the resulting increase in fuel consumption, brings along problems such as free time in traffic. Information technologies are used to solve transportation problems in smart cities. In addition to the concept of smart cities, "smart city solutions / applications" are basically integrated into the information technologies infrastructure systems of cities such as Urban Information Systems (UIS) and Geographical Information Systems (GIS), and energy, water, transportation, etc. These are Information Communication Technologies (ICT) supported applications that facilitate the provision and follow-up of many services offered in cities such as health, education and security and increase their quality (Wang et al., 2017). Geographic information systems have a wide application area as an effective spatial analysis tool used by many sectors. A central information system based on GIS offers an information technology framework that unites not only

\footnotetext{
* Corresponding author
} 
all stakeholders, but also all areas of smart city processes, from conceptualization, planning and development to maintenance. GIS has taken place in every phase of the planning and development of a smart city (Roche, 2014).

Decision problems that require spatial data and information are called spatial decision problems. Planning, site selection, natural resource management and disaster risk assessments can be given as examples spatial decision making. Since spatial decision problems require the evaluation of many criteria according to many criteria, they are examined by multi-criteria decision making (MCDM) (Batuk, Ozturk, 2010).

Creating a smart city may be possible if we have a GIS model that truly represents the world city. Designing or managing a smart city in an existing or new city demands an enormous spatially referenced database (Kumar, 2014). With this increasing data density coming from different sources, information should be managed rationally and on time in order to manage urban resources better. Cities are complex systems made up of many components and interacting with each other. Therefore, in order to facilitate situation analysis and make the best decisions, it is necessary to assign a central role to GIS to provide the fastest access to different layers of information. Location data now has a very important place in the decisionmaking process. At this point, GIS is see as an important component of smart city development. This indicates the necessity of using GIS technology and MCDM techniques in smart cities. Within the scope of this study, it is aimed to determine which of the existing intersection points in Kayseri province should be implemented with the smart intersection system by using Geographical Information Systems and AHP method.

In this study, the criteria affecting the location of the intersections where the smart intersection system will be applied according to the current situation in Kayseri province by using the MCDM method were examined. In addition to the literature review for the determination of the criteria, 4 criteria were determined as a result of interviews with the faculty members of Erciyes University, Department of Survey Engineering, Environmental Engineering, public institutions and experts from the private sector. While determining the weights of the criteria and their importance relative to each other, 4 experts filled the AHP pairwise comparison table, and then the weights and significance levels were determined according to the average criteria matrix by taking the average of these tables. By combining the weights determined by AHP method with spatial analysis maps produced by GIS, it was tried to determine potential intersections for Kayseri province where smart intersection could be set up.

\section{MATERIALS AND METHODS}

\subsection{Case Study}

This study has been performed in the center of Kayseri province, with an area of $16917,49 \mathrm{~km} 2$, is located between $38^{\circ}$ $18^{\prime}$ and $37^{\circ} 45^{\prime}$ northern latitudes and $34^{\circ} 56^{\prime}$ and $36^{\circ} 59^{\prime}$ eastern longitudes in Central Anatolia (Fig 1). It has a population of 1.4 million inhabitants. The most important and highest mountain of the province is Mount Erciyes, which is 3,916 $\mathrm{m}$ above sea level. The potential opportunities of the industrial, livestock farming, agricultural, and tourism are high.

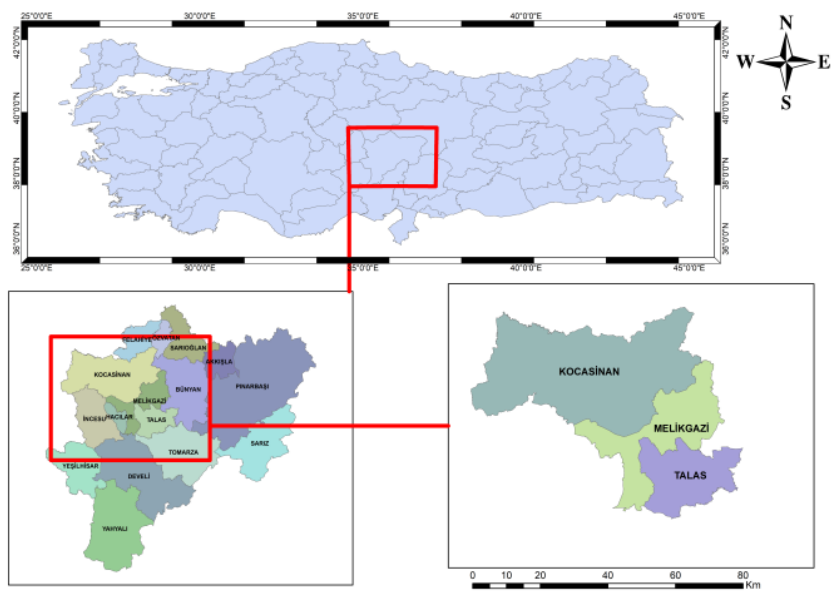

Figure 1. Study area

\subsection{Criteria}

After the study area was determined, the criteria to be used in choosing the right site for the smart intersection were decided. Smart intersections offer alternative solutions, especially at intersections, where there is traffic congestion during peak hours. With this system, instead of fixed signalling times, more dynamic times are assigned according to the traffic density, and with this, the waiting times of the traffic are minimized. Besides, it also controls the flow of traffic at intersections where accidents occur at a high rate. The criteria in Table 1 were determined in the selection of smart junction points by referring to the literature review and expert opinions.

\begin{tabular}{|c|}
\hline Criteria \\
\hline - Number of accidents at Intersections (C1) \\
\hline - Distance of fiber lines (C2) \\
\hline - Number of vehicles in intersections (morning) (C3) \\
\hline - Number of vehicles in intersections (evening) (C4) \\
\hline
\end{tabular}

The criterion for the number of accidents at intersections, one of the criteria to be used, includes the accident points from 2011 to 2018. Vehicle counts taken from Kayseri Metropolitan Municipality Traffic Signalization Branch Directorate are divided into evening and morning rush hours. First, the existing intersections were numbered and mapped. Also, the traffic density in the morning and evening was examined periodically and the intensity was observed mainly at the intersections at the entrance and exit hours.

\subsection{Analytic Hierarchy Process (AHP)}

Analytical Hierarchy Process (AHP), one of the most preferred multi-criteria decision making (MCDM) techniques in the literature, was first introduced by Myers and Alpert in 1968 and developed as a model by Saaty in 1980. AHP is frequently used in pre-feasibility, pre-study planning and project prioritization studies. Considering the usage areas of AHP, it is seen that it is a preferred method in many areas such as energy, education, environment, industry, construction public resources planning, strategic planning, and health. In AHP, the importance of the criteria and the weights of the criteria are determined using the pairwise comparison matrix (PCM). According to these weights, the decision-maker ("Which one will we choose?" or 
"Which is the best?") will find answers to the questions. (Haliloğlu, Odabaş, 2018) (Öztürk, Kılıç, 2010). In finding the weights with AHP, the first hierarchical structure is created. The criteria are compared, and as a result, which of the criteria are essential is determined. A comparison is made with the 1-9 scale evaluation chart created by Saaty. Finally, the weights and consistency rate of the criteria are calculated. If the consistency ratio is greater than 0.10 , it is understood that the values are inconsistent, and the pairwise comparison matrices are rechecked. To calculate the consistency ratio, the consistency index (CI) of the binary comparison matrix was calculated as $0.05(1)$.

$$
\begin{aligned}
& C I=\frac{(\lambda \max -n)}{(n-1)} \\
& C R=\frac{C I}{R I}
\end{aligned}
$$

To find the consistency ratio index (CR), it was taken as 0,90 for four criteria from the random indicator table of RI Saaty (2). If the consistency ratio is below 0,10 , it is accepted that the evaluations show sufficient consistency. If the consistency rate is above 0,10, pairwise comparisons are revised (Öztürk \& Kılıç, 2010). Decision matrices were created by four experts using the paired comparison method. The geometric mean of the decision matrices created by the decision-makers was taken, and then this matrix was normalized. The normalization matrix was formed, and after this process, the criterion weights were determined (Table 4).

The next step is to check the control of the pairwise comparison matrices by calculating the consistency ratio. To avoid possible inconsistency due to human error, the consistency ratio (CR) used in various similar studies was used. To calculate the consistency ratio, the consistency index $(\mathrm{CI})$ of the pairwise comparison matrix was calculated as 0,050 and the consistency ratio index (CR) as 0,045 . Paired comparison matrices are considered suitable because the consistency ratio is less than 0,10 .

\section{CASE APPLICATIONS}

In this section, the location of the optimum number of the most suitable intersection points has been made by using the smart intersection application GIS-based MCDM techniques that can be used in smart cities. It is seen that there are many studies in the literature that use GIS and MCDM techniques together.

Latinopoulos and Kechagia (2015) used a combination of GIS and MCDM methods to select suitable sites in wind farm projects. Villacreses et al. (2017) determined suitable areas for establishing wind-farms in the Ecuador region using GIS and MCDM methods.

\subsection{Smart Intersection}

Due to the increase in the population and the number of vehicles in the cities, transportation problems have started to rise. Traffic congestion and traffic accidents that cause loss of life and property are the most urgent problems. In addition to these, fuels burned by vehicles and gases from exhausts bring air and environmental pollution. Besides, the increase in fuel consumption contributes negatively to the country's economy. When people arrive at their homes and work in a mentally tense and stressful state, this also creates negative consequences for social peace. To solve these increasing problems in cities, the use of smart intersection systems supported by the facilities provided by ICT should be increased. However, for the management and planning of these systems, traffic control centers should be established in cities (Abdalla Ahmed et al., 2017).

In this section, the benefits of smart intersections and the working principle of the system will be examined. Traffic signaling systems, which are an essential element of smart transportation systems, provide effective, secure, and fluent management of traffic by using parameters such as planning, design, integration, maintenance, and operation.

Intelligent intersection control systems, which optimize light times depending on the number of vehicles in signalized intersections, reduce the waiting times of the vehicles. According to this system, green light durations are determined automatically. Also, the vehicle counting cameras included in this system obtain vehicle density data by counting the vehicles in the intersection arms using image processing techniques. This intensity data is sent to the system and analysed instantly, and the light durations at the intersection are continuously optimized. In this way, the waiting times of the vehicles at the lights are minimized. Another method is that the sensors placed in the intersections instantly make automatic counts and send to the system which vehicle is more on the intersection arm and gives the crossing superiority to that intersection branch (Abdalla Ahmed et al., 2017).

With the smart intersection system:

- Traffic flow will accelerate at intersections and road sections between intersections.

- Unnecessary waiting of vehicles at intersections will be prevented and the time lost by people in traffic will be minimized, waiting times and therefore time spent in traffic will be minimized.

- The rate of toxic gases and air pollutants released into the environment will be reduced.

- Contribution to the country's economy is provided by reducing fuel consumption.

- Red light violations and traffic accidents are reduced with the safe times produced by the system (Abdalla Ahmed et al., 2017).

\subsection{Number of Vehicles Passing by Intersections in the Morning and Evening}

In this section, a general framework will be drawn up by examining a busy intersection in Kayseri and giving the number of vehicles passing daily. The intersection, known as Kartal Crossroad (K1), was investigated.

Figure 3 shows the lanes and traffic flow directions on the counted branches.

\subsection{Number of Accidents Occurring at Intersections}

The number of accidents at intersections is an essential criterion for choosing a smart intersection. Intersections with a high number of accidents will be a priority for the smart intersection system. Figure 3 shows the density map created according to the number of accidents. 


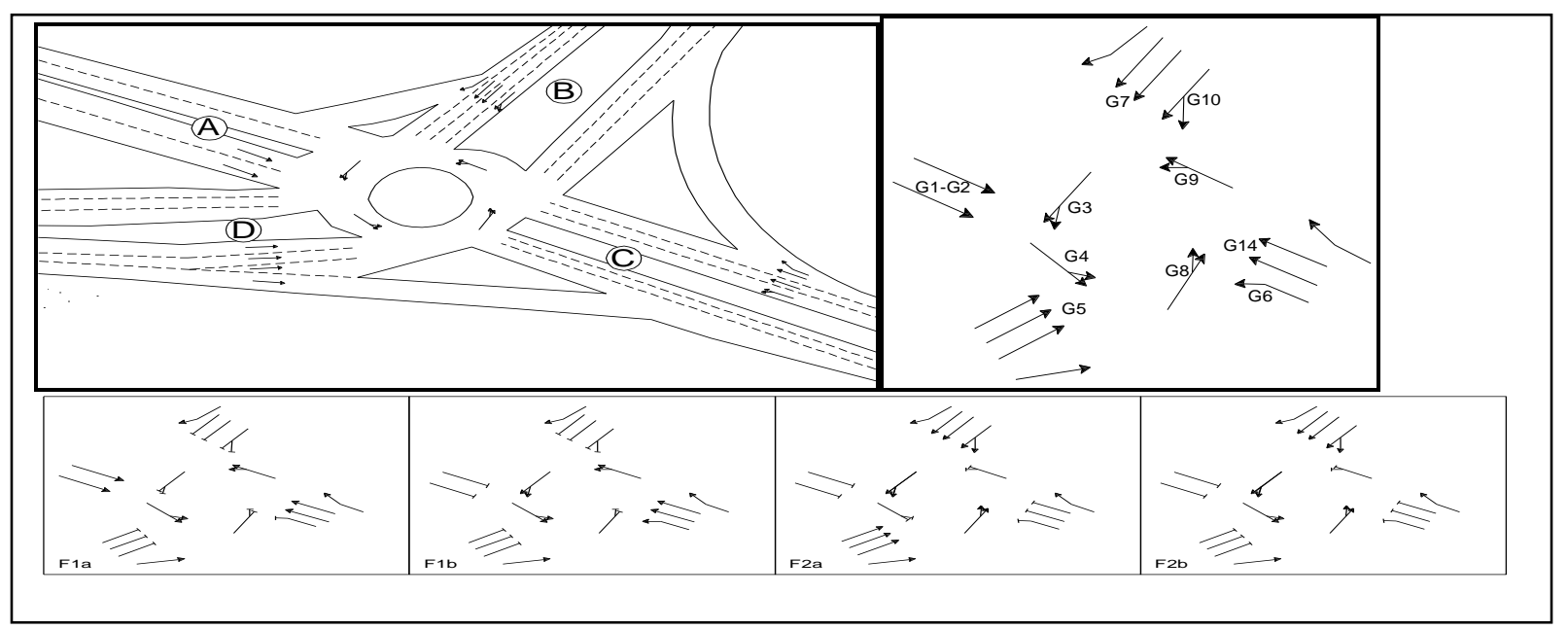

Figure 2. Lanes on the approach arms of K1 intersection and traffic flow directions

As can be seen in Table 2, the traffic load at the intersection in the morning hours is 13000 vehicles and the hourly traffic volume is around 6500 vehicles/hour.

\begin{tabular}{|c|c|c|c|c|c|c|c|c|c|c|c|c|c|c|c|c|c|}
\hline & $\mathbf{A}$ & & & & B & & & & C & & & & D & & & & \\
\hline & نี & $\stackrel{\varrho}{\circ}$ & $\stackrel{\pi}{\nu}$ & 号 & تే & $\stackrel{\mathscr{D}}{\mathscr{D}}$ & $\stackrel{\Xi}{\nabla}$ & 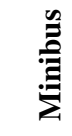 & Jె & $\stackrel{0}{A}$ & $\stackrel{\Xi}{\bar{\nu}}$ & 号 & ઇే & $\stackrel{\varrho}{\varrho}$ & $\stackrel{\Xi}{\nabla}$ & 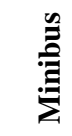 & 造 \\
\hline A & 0 & 0 & o & O & 79 & o & 0 & 9 & 475 & 221 & 6 & 85 & 0 & 0 & 0 & 0 & 875 \\
\hline B & 169 & 0 & $\mathbf{0}$ & 34 & 0 & O & 0 & 0 & 1302 & 124 & 20 & 139 & 1937 & 119 & 35 & 396 & 4275 \\
\hline C & 2510 & 272 & 14 & 160 & 76 & O & 0 & 16 & 3 & 0 & 0 & 0 & 1666 & 82 & 20 & 138 & 4957 \\
\hline D & 154 & 60 & 1 & 45 & 1464 & 148 & 25 & 436 & 476 & 23 & 0 & 108 & 0 & 0 & o & o & 2940 \\
\hline TOTAL & 2833 & 332 & 15 & 239 & 1619 & 148 & 25 & 461 & 2256 & 368 & 26 & 332 & 3603 & 201 & 55 & 534 & 13047 \\
\hline
\end{tabular}

Table 2. Traffic volume counts in the morning of K1 junction (07: 00-09: 00)

As can be seen in Table 3, the traffic load at the intersection in the evening hours is 15000 vehicles and the hourly traffic volume is around 7500 vehicles / hour.

\begin{tabular}{|c|c|c|c|c|c|c|c|c|c|c|c|c|c|c|c|c|c|}
\hline & \multicolumn{4}{|l|}{ A } & \multicolumn{4}{|l|}{ B } & \multicolumn{4}{|l|}{ C } & \multicolumn{4}{|l|}{ D } & \multirow[b]{2}{*}{ 氙 } \\
\hline & שَّ & $\stackrel{\varrho}{\Xi}$ & $\stackrel{\Xi}{\nabla}$ & 芑 & تَّ & $\stackrel{\theta}{=0}$ & $\underset{\nabla}{\Xi}$ & 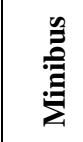 & Uె & $\stackrel{\varrho}{=}$ & $\underset{\nu}{\tilde{\pi}}$ & 号 & $\overline{\tilde{U}}$ & $\stackrel{\varrho}{\varrho}$ & $\stackrel{\Xi}{\nabla}$ & 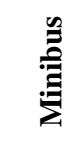 & \\
\hline A & O & O & O & 0 & 166 & 0 & 0 & 46 & 1334 & 76 & 0 & 66 & 0 & 0 & O & O & 1688 \\
\hline B & 100 & 0 & O & 3 & 0 & 0 & 0 & 0 & 1811 & 43 & 0 & 155 & 1902 & 54 & 14 & 244 & 4326 \\
\hline $\mathrm{C}$ & 1001 & 167 & O & 152 & 380 & 0 & 0 & 29 & O & 0 & 0 & 0 & 1504 & 45 & 3 & 141 & 3422 \\
\hline D & 213 & 10 & O & 25 & 3027 & \begin{tabular}{|l|}
93 \\
\end{tabular} & 9 & 385 & 1445 & 43 & 12 & 151 & 0 & O & O & O & 5413 \\
\hline TOTAL & 1314 & 177 & O & 180 & 3573 & \begin{tabular}{|l|}
93 \\
\end{tabular} & 9 & 460 & 4590 & 162 & 12 & 372 & 3406 & 99 & 17 & 385 & 14849 \\
\hline
\end{tabular}

Table 3. Traffic volume counts in the evening of K1 junction (16:00-18: 00)

When the tables are examined, it can be seen that the evening traffic volume is higher than the morning traffic volume and the critical peak hour is evening. For this reason, the number of evening and morning traffic was analysed separately. Traffic density maps are shown in Figure 3. 


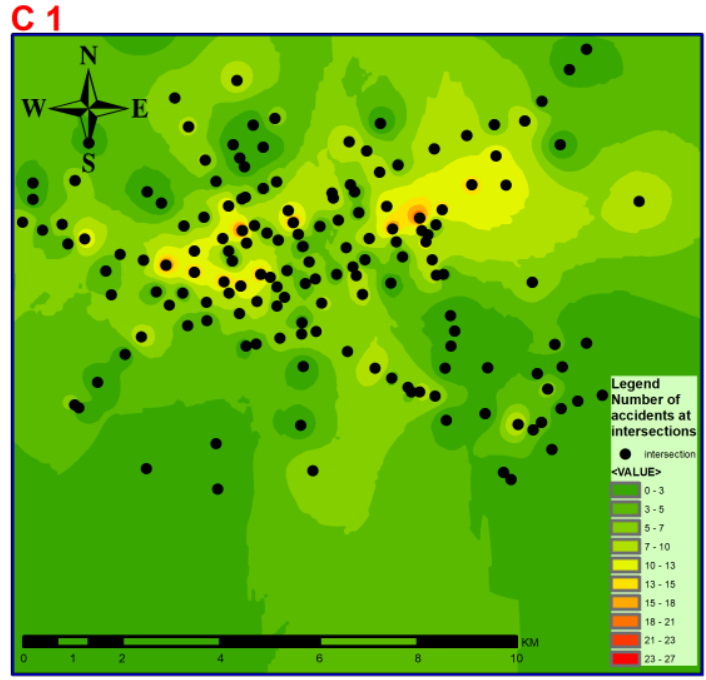

(a) Accident density

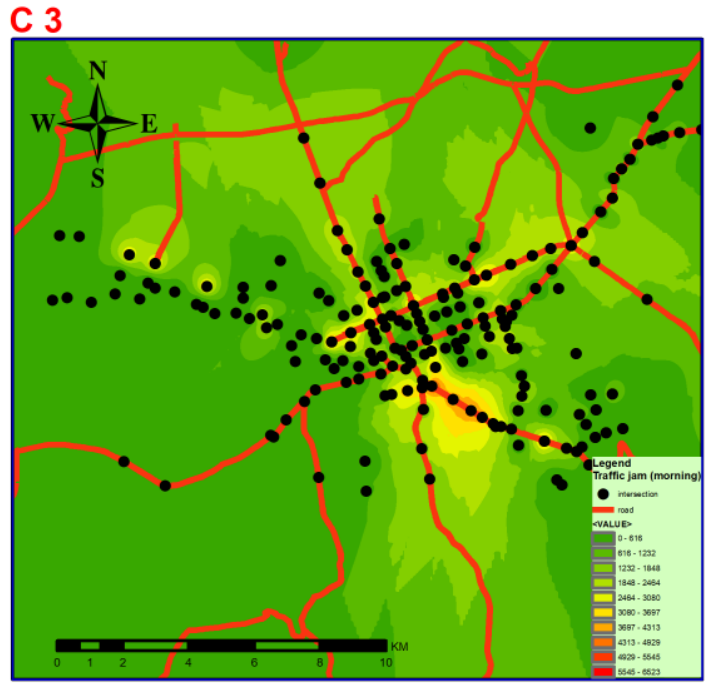

(c) Traffic jam (morning)

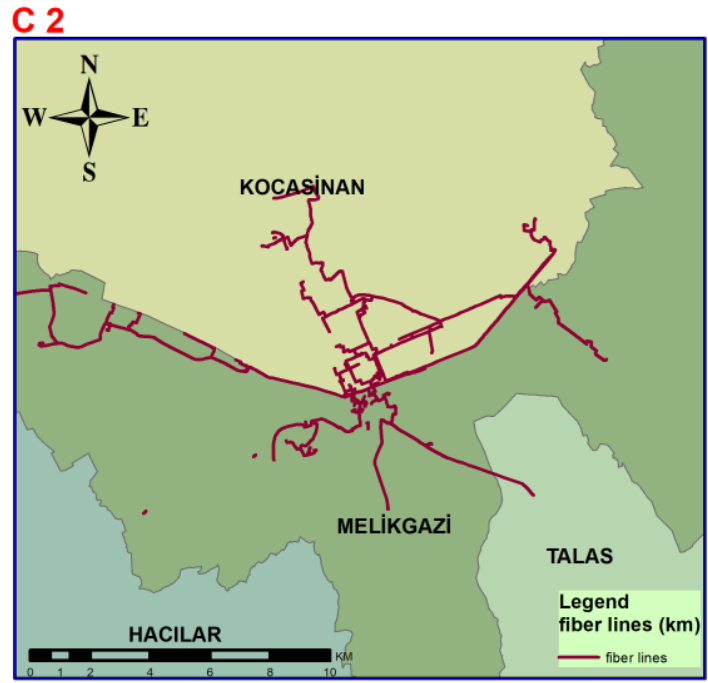

(b) Fiber lines

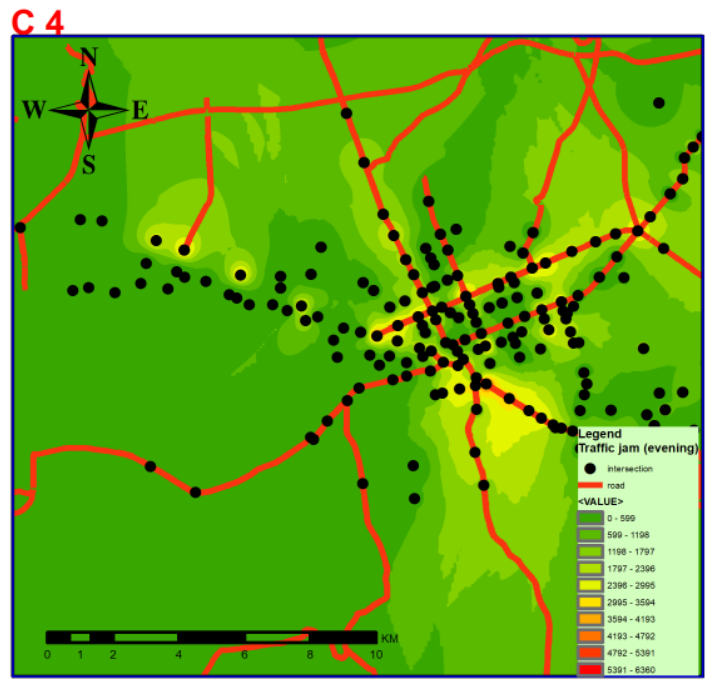

d) Traffic jam (evening)

Figure 3. Sub-criteria maps*.

* (a) Number of accidents at Intersections (b) Distance of fiber lines (c) Number of vehicles in intersections (morning) (d) Number of vehicles in intersections (evening)

\subsection{Classes Produce reclassification maps according to the constraint criteria}

Necessary actions were taken in ArcGIS according to the restrictions mentioned above. First, Euclidean distance was used for distance constraints. Distances were calculated for fiber lines. Since the data obtained after the Euclidean distance operation is in raster format, the reclassify process can be applied. Euclidean distance was not applied in the data of accident number, the number of vehicles in the morning, and the number of vehicles in the evening, so only reclassify was applied. For the province of Kayseri, selected as the study area, the criteria to be used within the scope of the study that is effective in the location of smart intersections are shown in Table 4. The conformity classes assigned according to the criteria in Table 4 are also determined as follows: not suitable $(0)$, very suitable (1), suitable (2), moderately suitable (3) poorly suitable (4), slightly suitable (5) (Table 3 ) 


\begin{tabular}{|l|c|l|c|}
\hline Criteria/Data sources & Unit & \multicolumn{1}{|c|}{$\begin{array}{c}\text { Suitability Score/ } \\
\text { Ranking a }\end{array}$} & Final Weight \\
\hline $\begin{array}{l}\text { C1. Number of } \\
\text { accidents at } \\
\text { Intersections }\end{array}$ & $\begin{array}{c}\text { number of } \\
\text { accidents }\end{array}$ & (0) $0-3(1) 13-27$ (2) $10-13$ (3) $7-10$ (4) $5-7(5) 3-5$ & $\mathbf{4 5}$ \\
\hline $\begin{array}{l}\text { C2. Distance of fiber } \\
\text { lines }\end{array}$ & $\mathrm{m}$ & (0) $100>$ (1) $0-10.7$ (2) $10-25(3) 25-45(4) 45-75(5) 75-100$ & $\mathbf{1 2}$ \\
\hline $\begin{array}{l}\text { C3. Number of vehicles } \\
\text { in intersections } \\
\text { (morning) }\end{array}$ & $\begin{array}{c}\text { number of } \\
\text { vehicles }\end{array}$ & $\begin{array}{l}\text { (0) } 0-616(1) 3080-6523 \text { (2) } 2464-3080 \text { (3) } 1848-2464 \text { (4) } 1232-1848 \\
\text { (5) } 616-1232\end{array}$ & $\mathbf{2 1}$ \\
\hline $\begin{array}{l}\text { C4. Number of vehicles } \\
\text { in intersections } \\
\text { (evening) }\end{array}$ & $\begin{array}{c}\text { number of } \\
\text { vehicles }\end{array}$ & $\begin{array}{l}\text { (0) } 0-599(1) 2995-6360 \text { (2) } 2396-2995 \text { (3) } 1797-2396 \text { (4) } 1198-1797 \\
\text { (5) } 599-1198\end{array}$ & $\mathbf{2 2}$ \\
\hline
\end{tabular}

Table 3. List of used criteria and ranking score.

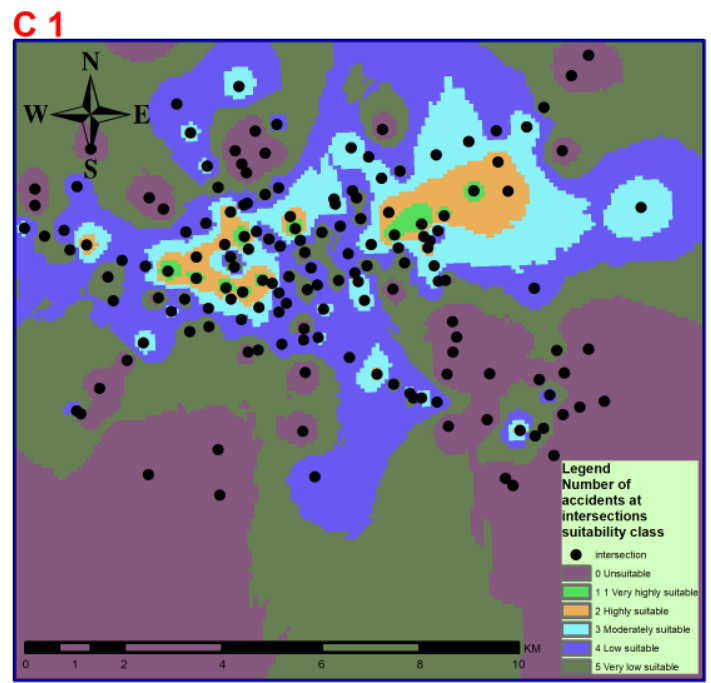

(a) Reclass accident density

C 3

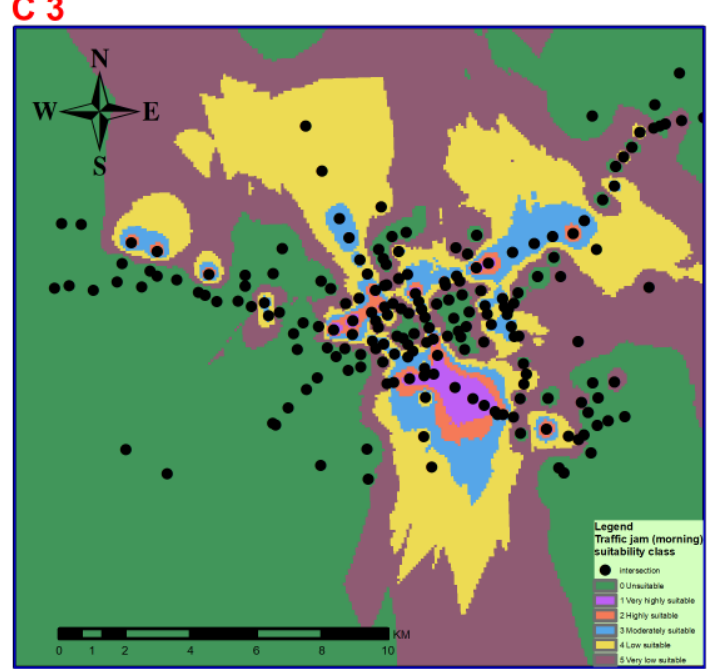

(c) Reclass traffic jam (morning)

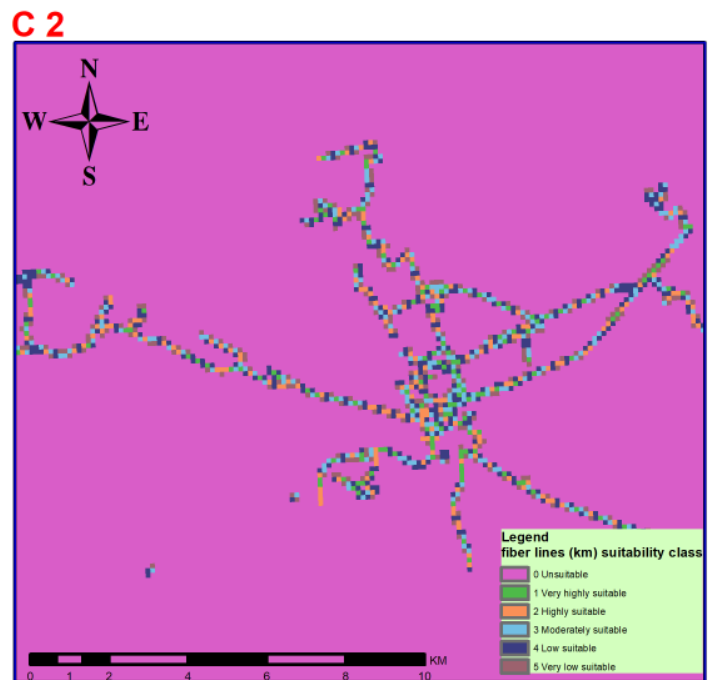

(b) Reclass fiber lines

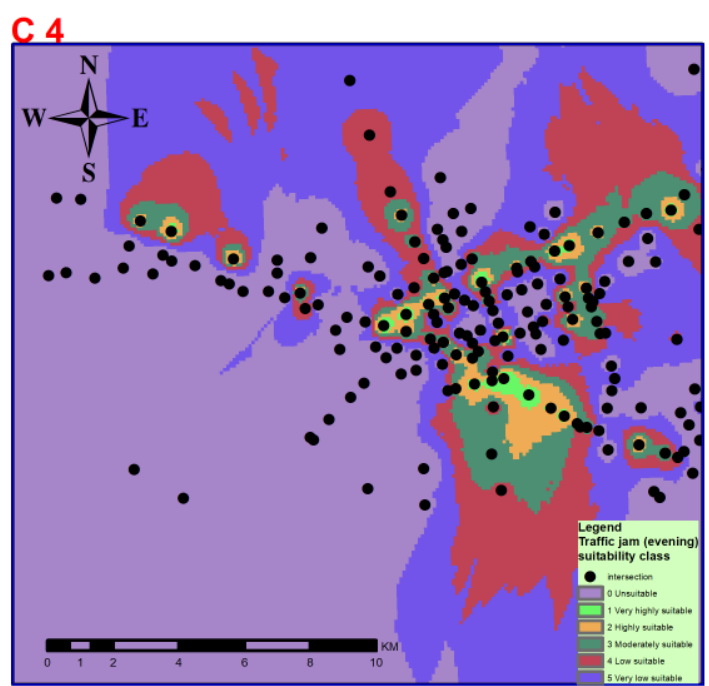

d) Reclass traffic jam (evening)

Figure 4. Reclassification maps used for four sub-criteria*.

* (a) Number of accidents at Intersections (b) Distance of fiber lines (c) Number of vehicles in intersections (morning) (d) Number of vehicles in intersections (evening) 


\subsection{Weighting the Criteria Affecting the Smart Intersection Location Selection by AHP Method}

Maps were created according to the four criteria determined in the ArcGIS software and the classes shown in Table 4 (Figure 4). Reclassification maps obtained by GIS analysis and criterion weights determined by the AHP method were combined with the "Weighted Overlay" method in the ArcGIS environment, and the resulting map was obtained. The weighted overlay tool is one of the approaches used to solve multi-criteria problems in selecting the appropriate area. The criteria maps are multiplied by the weights and then overlapped to get the resulting map. In this study, the criteria classification maps obtained in Figure 4 were overlapped by a weighted overlay method, and a smart intersection compliance map was created for the province of Kayseri (Figure 5).

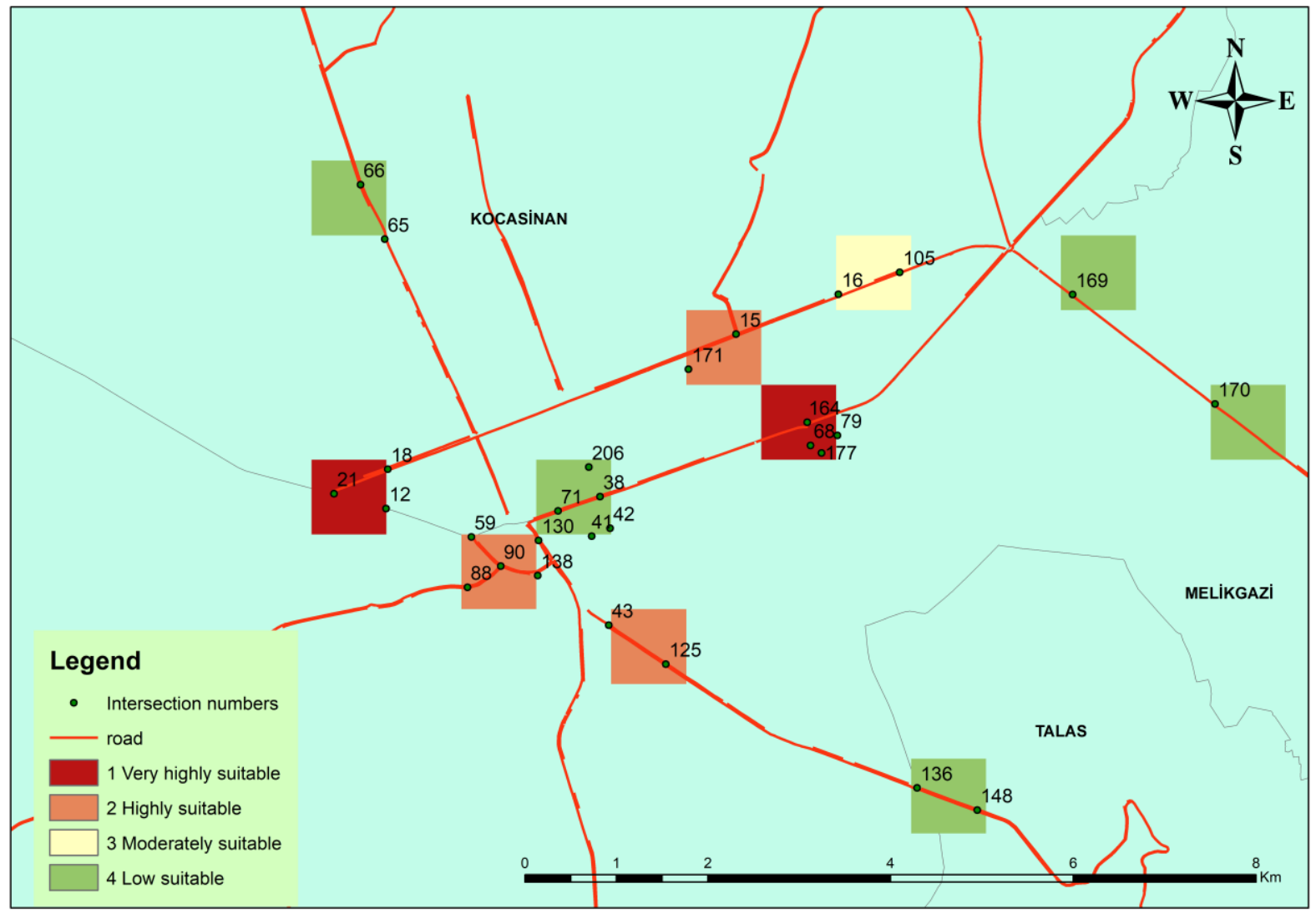

Figure 5. Smart intersection availability map

The intersections identified as ' 1 ' in the legend for Figure 5 mean that they are priority intersections for the smart intersection system. Although the intersections identified as '2' have not as much priority as ' 1 ', they are important intersection points where the smart intersection system should be applied. The intersections identified as ' 3 ' need a moderate intelligent intersection system, and the intersections identified as '4' are a low priority for the smart intersection system.

\section{DISCUSSION AND CONCLUSION}

For the smart intersection application, all intersections in the city center of Kayseri were evaluated according to the determined criteria, and the intersection points that most need smart intersections were determined. At this point, the distance criterion to fiber lines was taken into consideration in terms of the cost. At the same time, to prevent traffic problems and accidents, the number of vehicles and accident density criteria were also evaluated. As a result, it has been observed that the traffic is heavy throughout Kayseri and the intersections where accidents frequently occur need smart intersections. The next step after the smart intersections is the establishment of traffic control centers that intervene in congested traffic. Thus, drivers can be directed to alternative routes. With these practical solutions, smart transportation will provide high functionality and a more efficient flow. As a result of this study, an example is presented for the implementation of smart city applications in cities using GIS and the AHP method.

\section{REFERENCES}

Abdalla Ahmed, A.I., Gani, A., Ab Hamid, S.H., Khan, S., Guizani, N., Ko, K., 2017. Intersection-based distance and traffic-aware routing protocol for smart vehicular communication. 13th International Wireless Communications and Mobile Computing Conference (IWCMC), Valencia, 489493, doi: 10.1109/IWCMC.2017.7986334.

Batuk, F., Öztürk, D., 2010: Analytic hierarchy process for spatial decision making. Journal of Engineering and Natural Sciences, 28, 124-137.

Cengiz, N., Semsit, S., Ucar, A., 2017: Smart city implementations in the EU and reflections in Turkey. Suleyman Demirel University The Journal of Faculty of Economics and Administrative Sciences, 22(15), 1785-1798. 
Daniel, S., Doran, M., 2013. GeoSmartCity: Geomatics contribution to the Smart City. A.. Conference: 14th Annual International Conference on Digital Government Research: From e-Government to Smart Government. s. 65-71. Kanada.

Gruen, A., 2013: Smart cities: the need for spatial intelligence. Geospatial, 16(1), 3-6

Gruen A., (2013) A.Next generation smart cities- the role of geomatics. ISPRS WG IV/2. 2013. s. 25-41.

Geospatial World, GIS brings out the best in Smart Cities. https://www.geospatialworld.net/blogs/gis-smart-cities-gotogether/ (1 June 2019)

Kumar, V.T.M., 2014. Geographic information system for smart cities. New Delhi: Copal Publishing Group, s. 12-17.

Latinopoulos, D., Kechagia, K., 2015: A GIS-based multicriteria evaluation for wind farm site selection. A regional scale application in Greece. Renewable Energy, 78, 550-560.

Malczewski, J., Rinner, C., 2015. Multiattribute decision analysis methods. In Multicriteria Decision Analysis in Geographic Information Science Springer, Berlin, Heidelberg.

Sinmaz S., 2013: The Concept of "Smart Settlement" and Basic Principles in the Framework of New Developing Planning Approaches. Megaron, 8(2), 76-86.

Villacreses, G., Gaona, G., Martínez, J., Jijón, D., 2017: Wind farms suitability location using geographical information system (GIS), based on multi-criteria decision making (MCDM) methods: The case of continental Ecuador. Renewable Energy, 109, 275-286.

Wang, G., Qin, L., Li, G., Chen, L., 2009: Landfill site selection using spatial information technologies and AHP: a case study in Beijing, China. Journal of Environmental Management 90(8), 2414-2421. 